\title{
Power Quality in modern lighting: comparison of LED, microLED and CFL lamps
}

\author{
F. G. Montoya ${ }^{1}$ and J. Castillo ${ }^{1}$ \\ ${ }^{1}$ Department of Engineering \\ Area of Electrical Engineering \\ EPS, University of Almeria \\ Crtra. De Sacramento s/n, 04120 La Cañada de San Urbano, Almeria (Spain) \\ Phone/Fax number: +34 950 214501, e-mail: pagilm@ual.es, castillo.9@gmail.com
}

\begin{abstract}
This paper presents a study for the electric performance of different energy saving lamp types like LED, microLED and Compact Fluorescent Lamp (CFL), under nominal operating conditions (sinusoidal waveform of 230 Vrms and $50 \mathrm{~Hz}$ ) along with abnomal conditions such swells, sags, notch or harmonic distortion in the voltage source. A set of diferent test is also carried out for the selected lamps to determine the power quality values.
\end{abstract}

\section{Key words}

Lighting, Led, CFL, Power Quality, Harmonics

\section{Introduction}

In 2012, the lighting accounts for $10 \%$ of residential electricity consumption in the European Union countries (12\% in 2000) [1]. In the USA, the household lighting accounts for $11 \%$ in 2014 according to the US Energy Information Administration. This trend reflects a significant increase in the adoption of compact fluorescent lamps (CFLs) and light emitting diodes (LEDs) types in the past years at the expense of incandescent light bulb (IL) [1]. Although ILs and halogens type are cheaper to purchase, they are rather energy inefficient. Moreover, the U.S. Energy Independence and Security Act [2] and a European ban on incandescent bulbs type [3] have been enacted with the aim to enhance and increase energy efficiency and conservation for general lighting.

A strong indicator that confirms this trend is the fact that the consumers are replacing incandescent light sources with compact fluorescent lamp (CFL) type and light emitting diode (LED) bulb type that use about $70 \%$ and $85 \%$ less energy and have 10 and 50 times longer lifetimes, respectively $[4,5]$.

LEDs type have also important benefits and advantages like the absence of mercury in CFLs type and higher energy efficiency for indoor lighting [6], but as a part of their energy saving strategy and energy policy, nations across the world still promote the use of CFLs type.

Many researchers around the world focus in reducing electrical loading by using efficient energy lighting methods which has resulted in a high-level interest in replacing conventional incandescent lamp type with Compact Fluorescent Lamps type and LED lamp type [7].

Recently, LED lamp types are more widely accepted than CFLs type because of their important advantages in lower power consumption and longer lifetime. Also, LED lamps type, similar to CFLs type, are non-linear in nature and hence induce harmonics into the distribution system [7].

\section{Material and Methods}

\section{A. Lighting technology and type}

In this work, two main types of lighting sources have been chosen as the most used models in the market: LED and CFL.

LED's principle of operation has been widely studied $[8,9]$ and can be described as a two-lead semiconductor diode, which emits light when activated. When the electric current flows, electrons are able to recombine with holes within the device, releasing energy in the form of photons. Inside the semiconductor material of the LED, the electrons and holes are contained within energy bands. The separation of the bands (i.e. the bandgap) determines the energy of the photons (light particles) that are emitted by the LED. The photon energy determines the wavelength of the emitted light, and hence its colour. Different semiconductor materials with different bandgaps produce different colours of light. The precise wavelength (colour) can be tuned by altering the composition of the light-emitting, or active, region. Figure 1 shows the illustration of this process. 

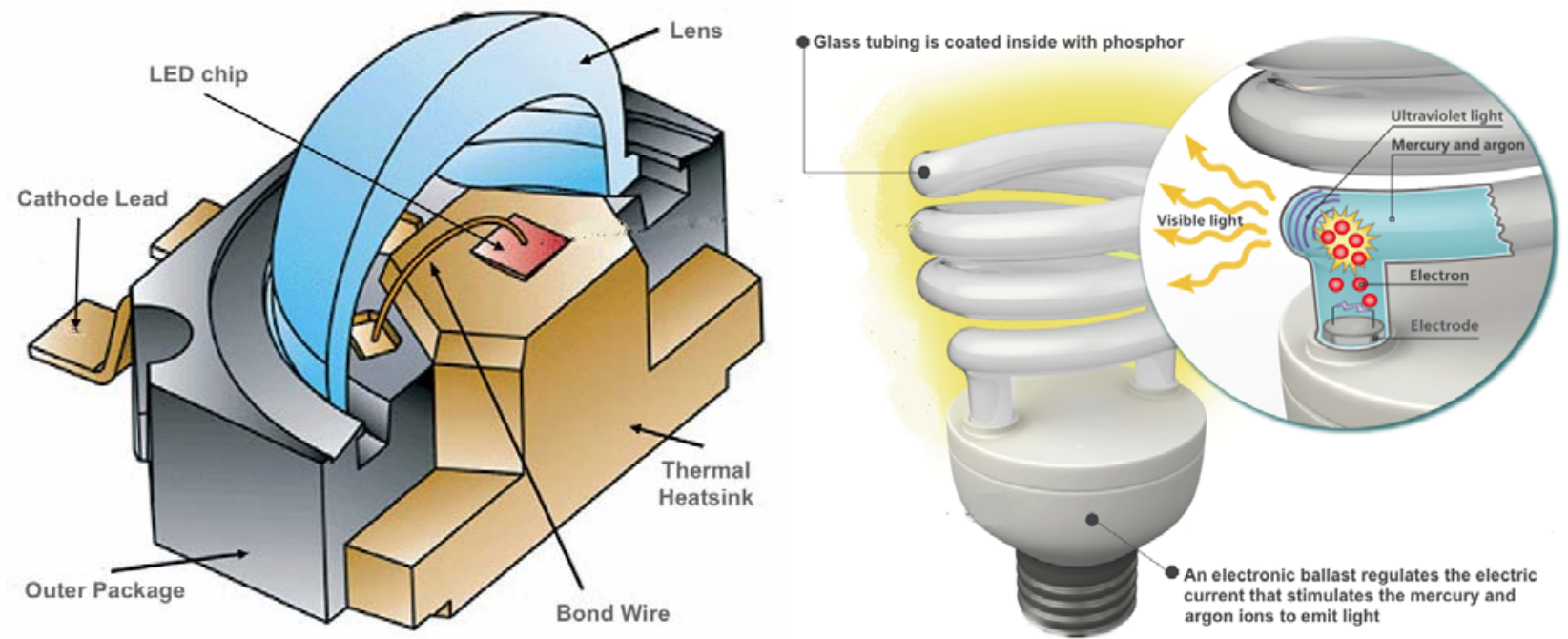

Fig. 1. Light emitting diode (LED) principle of operation (left) and Compact Fluorescent Lamp (CFL) principle of operation (right). Adapted from http://ehp.niehs.nih.gov.
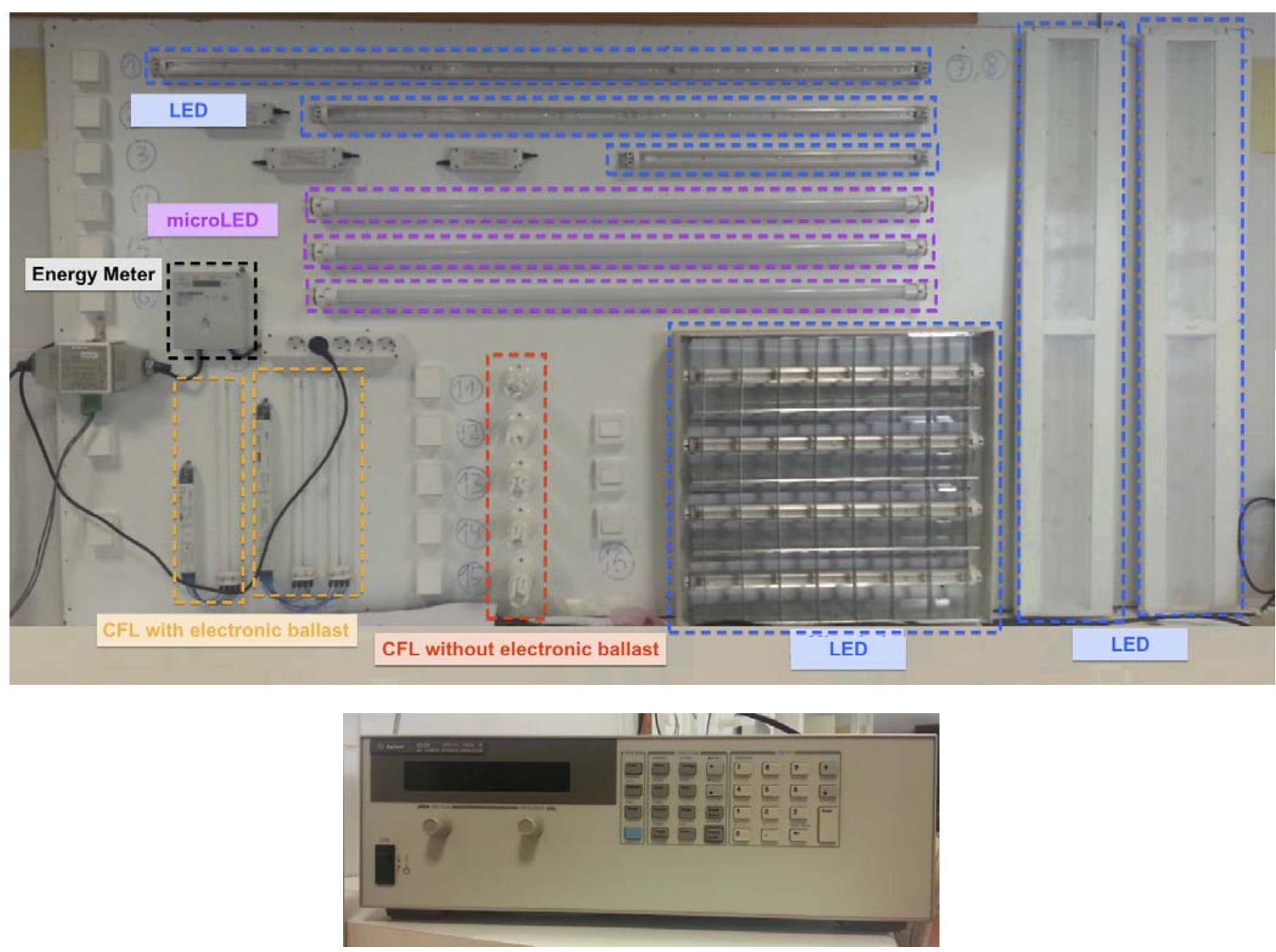

Fig. 2. Experimental setup with LED, microLED and CFL lamps (up) and Agilent 6812B digital power source (bottom).

The principle of operation in a CFL bulb is exactly the same as the fluorescent lighting: electrons that are bound to mercury atoms are excited to states where they will radiate ultraviolet light as they return to a lower energy level; this emitted ultraviolet light is converted into visible light as it strikes the fluorescent coating on the bulb (as well as into heat when absorbed by other materials such as glass). The main drawback compared to LED and, especially, incandescent is the content of hazardous elements like lead, zinc and mercury.

A total of 16 different lamp types have been used for the tests carried in this work (see Table I). The energy consumed was also registered with a digital energy totalizer. Up to 4 different lamp types were employed, including LED, microLED and CFL with and without 
electronic ballast (CFL1 and CFL2, respectively). However, two main groups can be considered upon the basis of their operating principle, i.e., luminescence for CFL lamps and electro luminescence for LED and microLED lamps. No incandescent lamp has been tested because of their obsolescence and its ban by the European laws [3]. The figure 2 shows the setup in the laboratory.

Table I. - Lamp types

\begin{tabular}{c|crccc}
\hline Lamp & Type & $\begin{array}{c}\text { Power } \\
\text { (W) }\end{array}$ & $\begin{array}{c}\text { Lifespan } \\
\text { (h) }\end{array}$ & $\begin{array}{c}\text { Luminous } \\
\text { efficacy } \\
(\mathbf{L m} / \mathbf{W})\end{array}$ & $\begin{array}{c}\text { Colour } \\
\text { Temp } \\
\left({ }^{\mathbf{o}} \mathbf{K}\right)\end{array}$ \\
\hline $\mathbf{1}$ & LED & 14.3 & 50000 & 94 & 4000 \\
$\mathbf{2}$ & LED & 12.7 & 50000 & 94 & 4000 \\
$\mathbf{3}$ & LED & 7.9 & 50000 & 94 & 4000 \\
$\mathbf{4}$ & MicroLED & 18 & 50000 & 80 & 5500 \\
$\mathbf{5}$ & MicroLED & 18 & 50000 & 80 & 5500 \\
$\mathbf{6}$ & MicroLED & 18 & 50000 & 80 & 5500 \\
$\mathbf{7}$ & LED & 36 & 50000 & 94 & 4000 \\
$\mathbf{8}$ & LED & 36 & 50000 & 94 & 4000 \\
$\mathbf{9}$ & CFL1 & 36 & 10000 & 80 & 4000 \\
$\mathbf{1 0}$ & CFL1 & 72 & 10000 & 80 & 4000 \\
$\mathbf{1 1}$ & CFL2 & 20 & 10000 & 60 & 4000 \\
$\mathbf{1 2}$ & CFL2 & 20 & 10000 & 60 & 4000 \\
$\mathbf{1 3}$ & CFL2 & 20 & 10000 & 60 & 4000 \\
$\mathbf{1 4}$ & CFL2 & 20 & 10000 & 60 & 4000 \\
$\mathbf{1 5}$ & CFL2 & 20 & 10000 & 60 & 4000 \\
$\mathbf{1 6}$ & LED & 36 & 50000 & 94 & 4000 \\
\hline
\end{tabular}

\section{B. Power source}

The digital power supply Agilent HP6834B with arbitrary waveform output was used as the programmable power source. It combines the capabilities of a power amplifier and an arbitrary waveform generator. This allows simulating normal waveforms and many types of distorted power waveforms. The built in power analyser combines the capabilities of a multimeter, oscilloscope, harmonic analyser and power analyser. The power supply has extensive 16-bit precision measurement capabilities and also includes:

- $\quad$ RMS, DC, AC + DC voltage and current

- Peak voltage and current

- $\quad$ Real, apparent, and reactive power

- Harmonic analysis of voltage and current waveforms providing amplitude and phase up to the 50th harmonic

- $\quad$ THD (total harmonic distortion)

\section{Cases of Study}

Several experiments have been carried out to test different combination of lamps and voltage waveform conditions. Three groups of trials have been established and results were obtained for each of them based on the voltage source conditions applied:

- Nominal voltage

- Transient voltage

- Distorted harmonic voltage

\section{A. Nominal voltage operating conditions}

As previously stated, a total of 16 lamps of different types (LED, microLED and CFL with and without electronic ballast) were used in the tests. Nominal voltage was generated using the Agilent power source, i.e., perfect sinusoidal of 230 RMS voltage and $50 \mathrm{~Hz}$ frequency (eq. 1).

$$
v(t)=\sqrt{2} \cdot 230 \sin (2 \pi 50 t+\varphi)
$$

Several power electric parameters were measured in order to categorise the severity of the distortion produced by the non-linear load lamp electric equivalent. Namely, RMS current, active power, reactive power, apparent power, distortion power, harmonic content, power factor, THD and peak current.

Figure 3 shows the current waveform for all the lamp type under test. It can be noted that LED lamp 1,2 and 3, and, especially, CFL2 lamps present a high distorted shape. That means there is a strong presence of harmonics in the demanded current of these types of lamps. Table II shows the main measured power values for this configuration.

Table II. - Power values under nominal conditions

\begin{tabular}{c|rrrrr}
\hline Lamp & $\begin{array}{c}\text { THDi } \\
\text { (\%) }\end{array}$ & $\begin{array}{c}\text { Active } \\
\text { Power } \\
\text { (W) }\end{array}$ & $\begin{array}{c}\text { Reactive } \\
\text { Power } \\
\text { (VAr) }\end{array}$ & $\begin{array}{c}\text { Distorted } \\
\text { Power } \\
\text { (VAd) }\end{array}$ & cos $\boldsymbol{}$ \\
\hline $\mathbf{1}$ & 21.96 & 14.33 & -8.70 & 3.84 & 0.83 \\
$\mathbf{2}$ & 25.34 & 12.72 & -8.42 & 3.94 & 0.83 \\
$\mathbf{3}$ & 36.21 & 7.85 & -5.84 & 5.83 & 0.69 \\
$\mathbf{4}$ & 18.71 & 20.07 & -8.82 & 3.54 & 0.90 \\
$\mathbf{5}$ & 15.84 & 19.26 & -8.55 & 3.39 & 0.90 \\
$\mathbf{6}$ & 16.03 & 19.97 & -8.63 & 3.44 & 0.91 \\
$\mathbf{7}$ & 12.64 & 36.24 & -9.24 & 4.99 & 0.96 \\
$\mathbf{8}$ & 12.57 & 36.27 & -9.23 & 4.86 & 0.96 \\
$\mathbf{9}$ & 19.54 & 33.47 & -9.81 & 7.09 & 0.94 \\
$\mathbf{1 0}$ & 13.67 & 60.37 & -15.84 & 9.05 & 0.96 \\
$\mathbf{1 1}$ & 107.21 & 19.55 & -9.03 & 22.91 & 0.62 \\
$\mathbf{1 2}$ & 112.69 & 19.81 & -9.16 & 24.04 & 0.61 \\
$\mathbf{1 3}$ & 107.44 & 19.25 & -8.95 & 22.39 & 0.62 \\
$\mathbf{1 4}$ & 104.58 & 18.96 & -8.64 & 22.29 & 0.62 \\
$\mathbf{1 5}$ & 105.11 & 19.92 & -9.35 & 22.94 & 0.63 \\
$\mathbf{1 6}$ & 18.81 & 32.41 & -14.80 & 6.04 & 0.90 \\
\hline
\end{tabular}

Note that for all lamps, the reactive power is negative, so it means they behave as capacitive loads. CFL1 lamps present a THDi above the rest along with a high distortion power $\mathrm{D}$.

The figure 4 shows the current waveform and the Fourier analysis when all the lamps are connected at the same time. Notice the relevance of harmonics up to $9^{\text {th }}$ order $(450 \mathrm{~Hz})$.

\section{B. Transient voltage operating conditions}

In order to emulate situations where transient voltage occurs, such sags, swells or notches, the HP6834B power source has been programmed accordingly. The tests revealed that neither sags nor swells produced harmful 


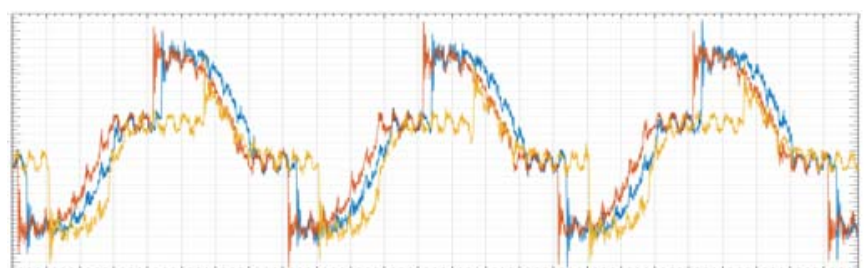

(a)

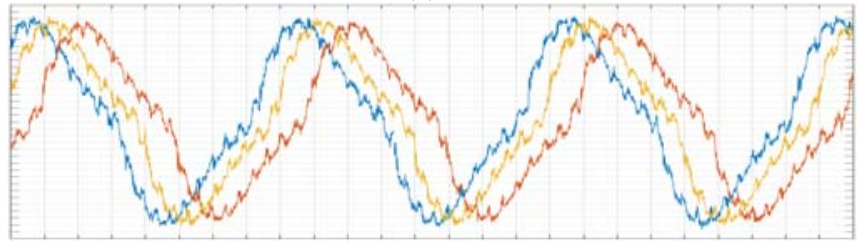

(c)

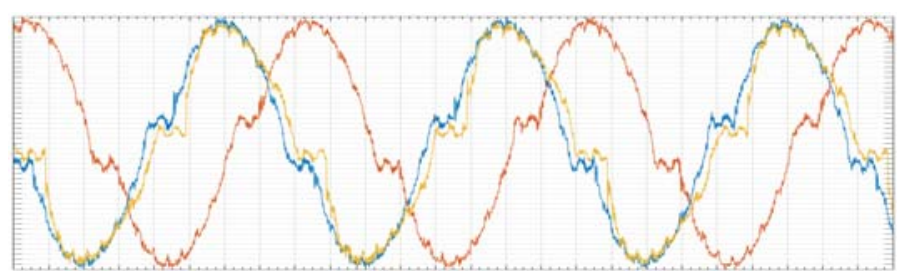

(b)

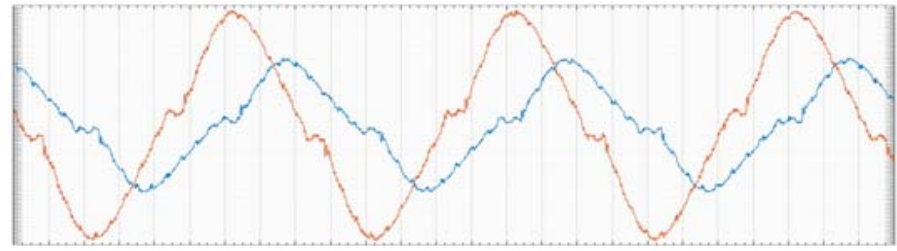

(d)
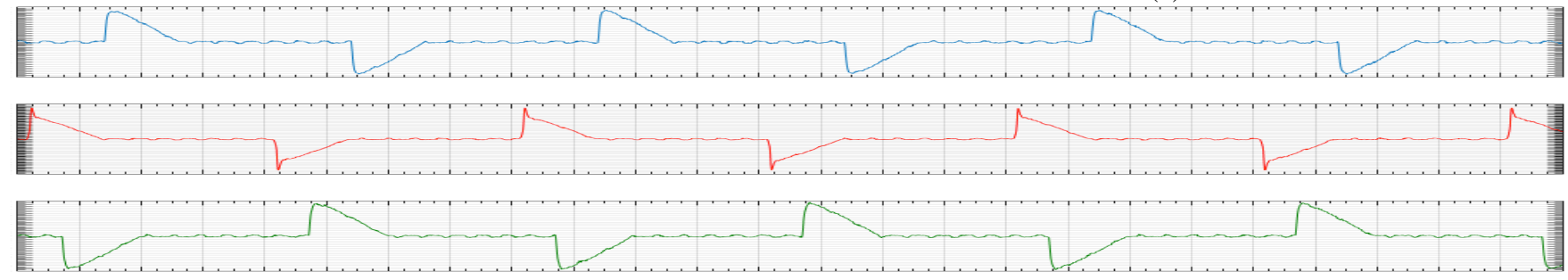

(e)

Fig. 3. Current waveform for lamps (a) 1,2,3 LED; (b) 7,8,16 LED; (c) 4,5,6 microLED; (d) 9,10 CFL1; (e) 11,12,13 CFL2
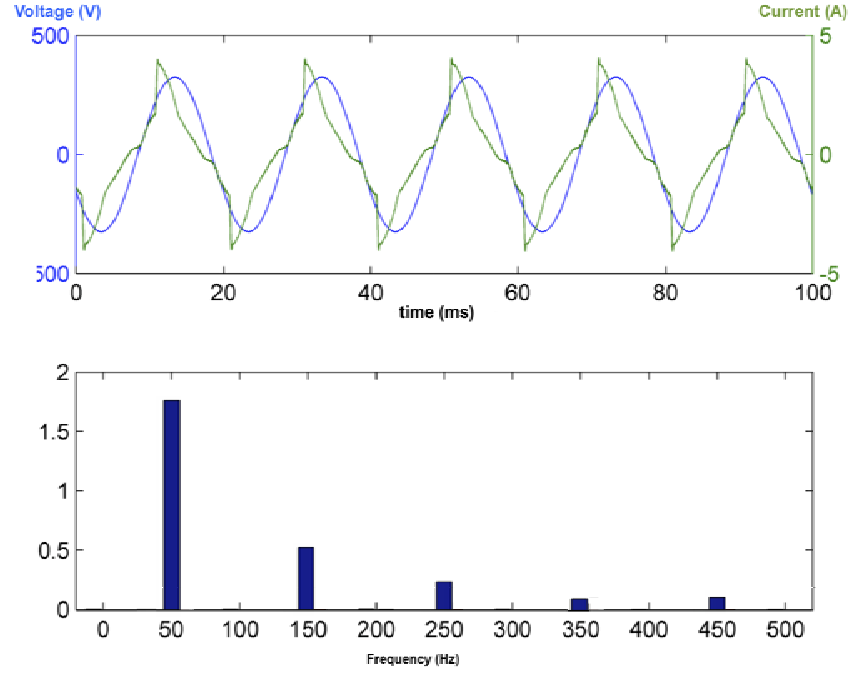

Fig. 4. Current waveform for the 16 lamps set (up) and Fourier analysis (bottom)

effects beyond the observed in nominal conditions. However, notches were identified as a potential source of damages for the lamps. To demonstrate this situation, notches of a maximum of $3 \mathrm{~ms}$ were added to the nominal voltage source in eq. (1). Figure 5 shows an example of such transient phenomenon. Similar waveform was applied to lamps 1, 4, 10 and 11 being representative of the four different types. Additionally, phase jumps were taken into account for the notch in $15^{\circ}$ steps, starting from $0^{\circ}$ to $90^{\circ}$. Figure 6 shows a detailed view of the result for a specific phase jump. It can be noted that high current peaks compared to nominal values are present in all lamp types, regardless of the phase jump, except for lamp 11 (CFL2 type) where the peak value was very dependent on phase. LED type lamp showed the poorest behaviour with a current peak over 16 times its nominal value. Also CFL2 presented a bad performance with 12.35 . On the contrary, CFL1 peak is only 4.5 times higher than nominal value.

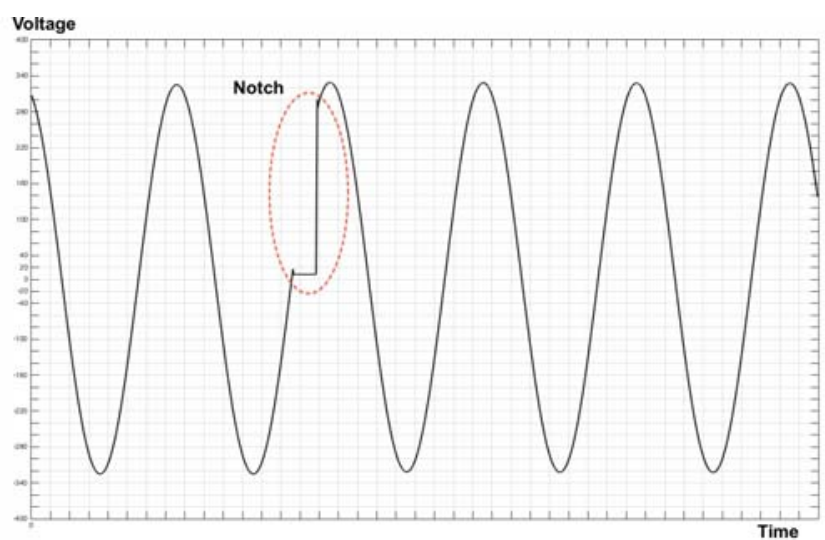

Fig. 5. Notch in voltage source

\section{Distorted harmonic voltage operating conditions}

In this experiment, the voltage applied to the lamps was formed by adding some harmonics to the fundamental. In particular, the harmonic spectrum was the following:

- Fundamental 230 Vrms.

- $\quad$ Third harmonic of $20 \%$.

- $\quad$ Fifth harmonic of $10 \%$.

- Seventh harmonic of 5\%.

Only odd harmonics were taken into account (even harmonics are almost negiglible in real power networks). Figure 7 shows the results for lamp 1, 4, 10 and 11. It can be noted the high current distortion caused by the voltage harmonics. Table III also shows the THDi increment for the distorted test compared to the nominal test. As a consecuence of the harmonic addition, the distortion level for the current is higher than the obtained in nominal conditions, except for lamp 11 (CFL2). As can be seen in Figure 7, lamp 1, 4 and 10 present a waveform with 
higher distortion compared to Figure 3, in contrast with lamp 11 where the new waveform looks less distorted as the THDi confirms in Table III. This can be explained assuming the poorer waveform for lamp 11 under nominal condition, so the new voltage harmonics are causing an improvement at the expense of the cancellation of some old harmonics.

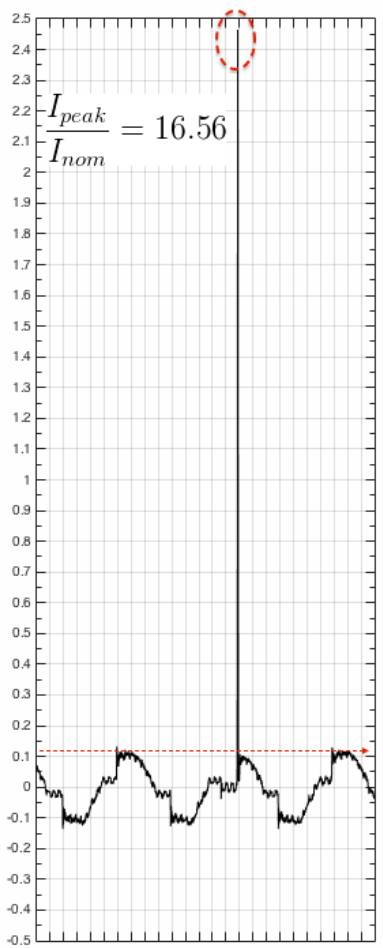

LED

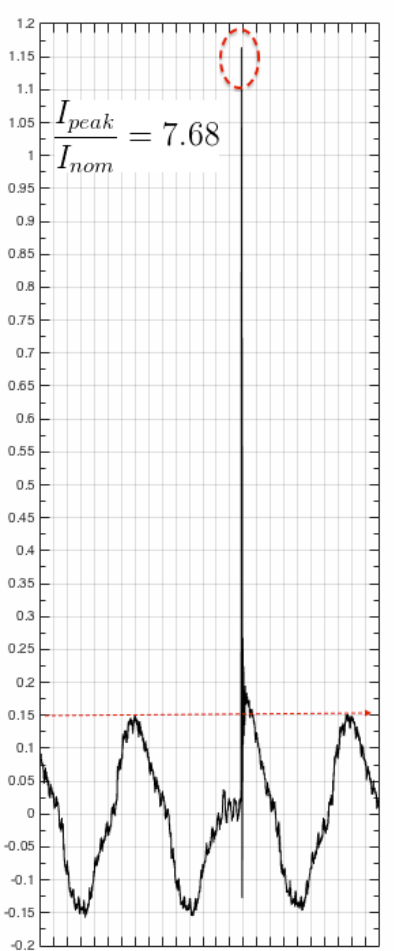

microLED

Table III. - Distortion comparison. Nominal conditions vs distorted harmonic conditions

\begin{tabular}{c|ccc}
\hline Lamp & $\begin{array}{c}\text { THDi \% } \\
\text { (nominal) }\end{array}$ & $\begin{array}{c}\text { THDi \% } \\
\text { (distorted) }\end{array}$ & $\begin{array}{c}\text { Increment } \\
\mathbf{( \% )}\end{array}$ \\
\hline $\mathbf{1}$ & 21.96 & 44.99 & 104.87 \\
$\mathbf{4}$ & 18.71 & 30.40 & 62.48 \\
$\mathbf{1 0}$ & 13.67 & 22.53 & 64.81 \\
$\mathbf{1 1}$ & 107.21 & 87.92 & -17.99 \\
\hline
\end{tabular}

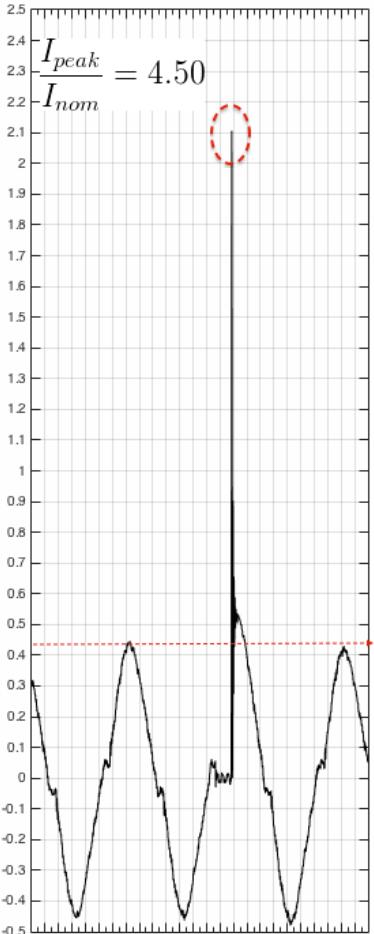

CFL1

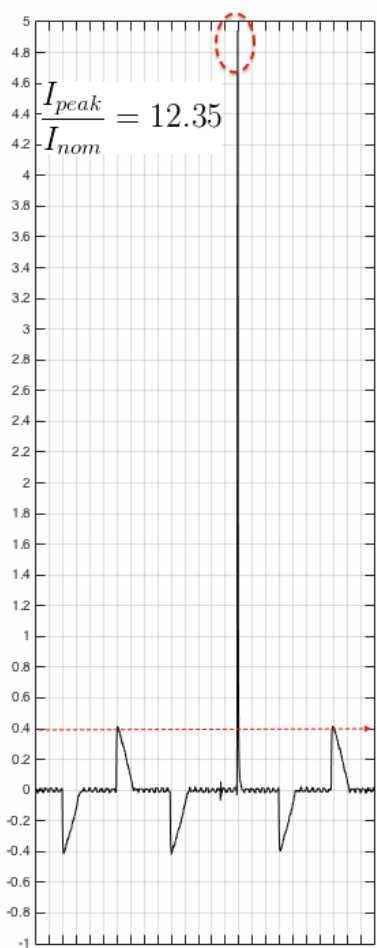

CFL2

Fig. 6. Current peaks for lamps 1, 4, 10 and 11 under transient notch voltage.
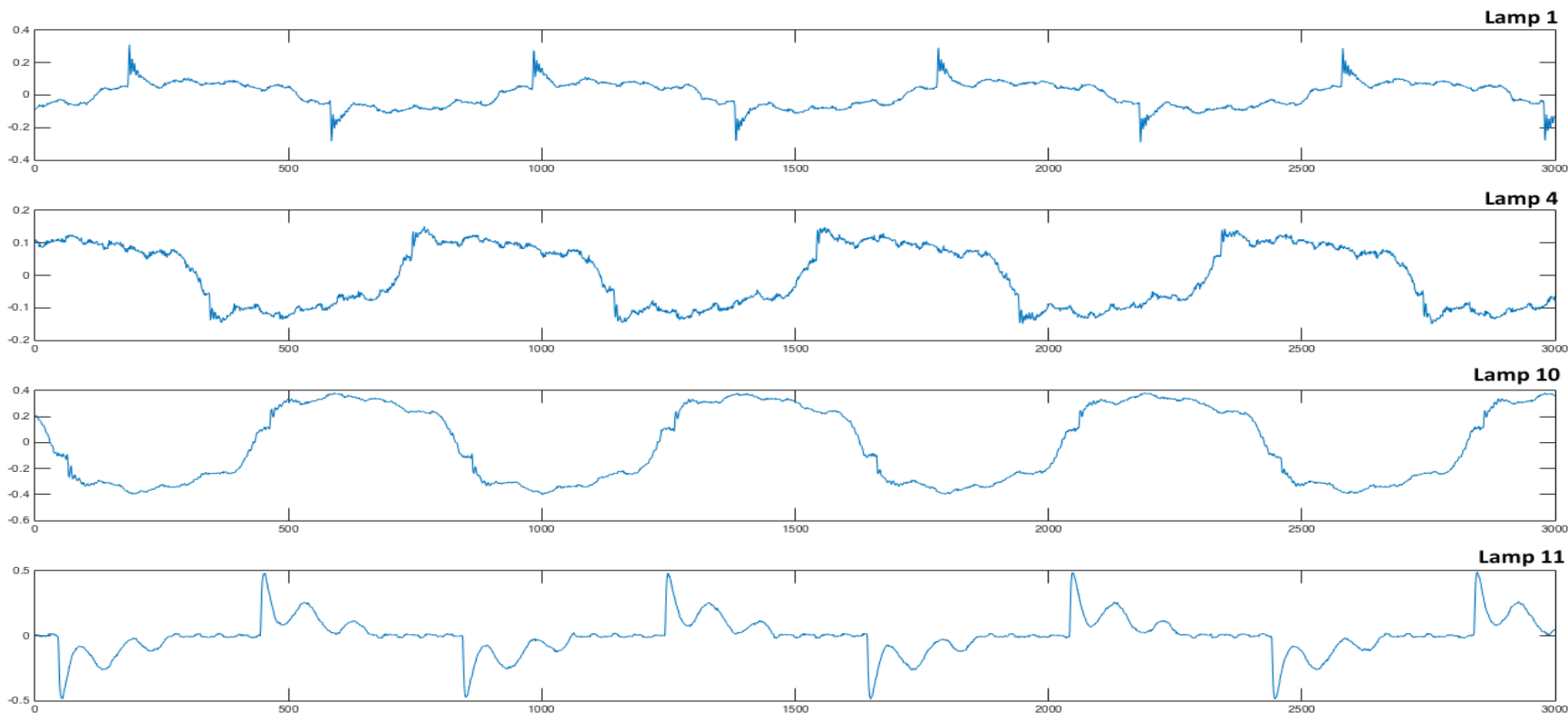

Fig. 7. Current distortion for lamps 1, 4, 10 and 11 under harmonics voltage. 


\section{Conclusion}

Various types of energy saving lamps used in general lighting have been analysed for their power quality properties under laboratory conditions. It is well known that modern lighting is an important source of harmonics and can cause bad power quality in the electrical system. The study of such source of harmonics will in fact help to avoid malfunction of other equipment connected to the grid. The measurements carried out in this work show that CFL equipment without electronic ballast are, by far, the worst lamp type because of their high emission of harmonics. On the contrary, CFL with electronic ballast, LED and microLED showed moderated harmonic emission. In other words, power quality concerns should be a reason for not using CFL lamps with electromagnetic ballast.

Measurement under transient and distorted voltage yielded bad results, especially when notches arise, causing peak overcurrent up to 16.5 times higher than nominal values. The spectrum obtained in the test showed a wide range in emission levels.

\section{Acknowledgement}

The authors wish to gratefully acknowledge financial support for this research sponsored by regional government Junta de Andalucía (Spain) through the grant Project of Excellence "Analysis of electric power quality using smart meters. Optimisation and savings in the production and residential sector in Andalusia" (P10RNM-6349).

\section{References}

[1] P. Bertoldi, N. Labanca, and B. Hirl, "Energy Efficiency Status Report 2012: Electricity Consumption and Efficiency Trends in the EU-27”, European Commission. Joint Research Centre. Institute for Energy and Transport (2012)

[2] Energy Independence. "Security Act of 2007." Public law 110, no. 140 (2007): 19.

[3] Energy Efficiency Directive. "Directive 2012/27/EU of the European Parliament and of the Council of 25 October 2012 on energy efficiency, amending Directives 2009/125/EC and 2010/30/EU and repealing Directives 2004/8/EC and 2006/32." Official Journal, L 315 (2012), pp. 1-56.

[4] P. Mottier, LED for lighting applications, John Wiley \& Sons, (2010).

[5] Energy Savings Estimates of Light Emitting Diodes in Niche Lighting Applications, U.S. Department of Energy, (2008).

[6] D. MacIsaac, G. Kanner, and G. Anderson. "Basic physics of the incandescent lamp (lightbulb)." The Physics Teacher 37, no. 9 (1999), pp 520-525.

[7] V. George, A. Bagaria, P. Singh, S. R. Pampattiwar, and S. Periwal, "Comparison of CFL and LED lamp-harmonic disturbances, economics (cost and power quality) and maximum possible loading in a power system." In Utility Exhibition on Power and Energy Systems: Issues \& Prospects for Asia (ICUE), 2011 International Conference and, pp. 1-5. IEEE, 2011.

[8] S. Pimputkar, J. S. Speck, S. P. DenBaars, and S. Nakamura. "Prospects for LED lighting." Nature Photonics 3, no. 4 (2009), pp 180-182.
[9] M. H. Crawford, "LEDs for solid-state lighting: performance challenges and recent advances." Selected Topics in Quantum Electronics, IEEE Journal of 15, no. 4 (2009), pp 1028-1040. 